\title{
The Effect of an Education Module to Reduce Weight Bias among Medical Centers Employees: A Randomized Controlled Trial
}

\author{
Shiri Sherf-Dagan ${ }^{a, b} \quad$ Yafit Kessler ${ }^{a, c} \quad$ Limor Mardy-Tilbor $^{b} \quad$ Asnat Raziel $^{c}$ \\ Nasser Sakran ${ }^{c, d, e}$ Mona Boaz ${ }^{\text {a }}$ Vered Kaufman-Shriqui ${ }^{a}$ \\ aDepartment of Nutrition Sciences, School of Health Sciences, Ariel University, Ariel, Israel; bepartment of \\ Nutrition, Assuta Medical Center, Tel Aviv, Israel; 'Assia Medical Group, Assuta Medical Center, Tel Aviv, Israel; \\ ${ }^{\mathrm{d}}$ Department of Surgery, Holy Family Hospital, Nazareth, Israel; ${ }^{\mathrm{e} T h e}$ Azrieli Faculty of Medicine Safed, Bar-llan \\ University, Ramat Gan, Israel
}

\section{Keywords \\ Obesity · Weight bias - Weight stigma - Weight \\ discrimination $\cdot$ Healthcare professionals}

\begin{abstract}
Introduction: Weight bias, stigma, and discrimination are common among healthcare professionals. We aimed to evaluate whether an online education module affects weight bias and knowledge about obesity in a private medical center setting. Methods: An open-label randomized controlled trial was conducted among all employees of a chain of private medical centers in Israel $(n=3,290)$. Employees who confirmed their consent to participate in the study were randomized into intervention or control (i.e., "no intervention") arms. The study intervention was an online 15-min educational module that included obesity, weight bias, stigma, and discrimination information. Questionnaires on Anti-Fat Attitudes (AFA), fat-phobia scale (F-scale), and beliefs about the causes of obesity were answered at baseline (i.e., right before the intervention), 7 days, and 30 days post-intervention. Results: A total of 506, 230, and 145 employees responded to the baseline, 7-day, and 30-day post-intervention questionnaires, respectively. Mean participant age was $43.3 \pm 11.6$ years, $84.6 \%$ were women, and $67.4 \%$ held an
\end{abstract}

Karger@karger.com www.karger.com/ofa

Karger!"

GOPEN ACCESS
C 2022 The Author(s).

Published by S. Karger AG, Basel

This is an Open Access article licensed under the Creative Commons Attribution-NonCommercial-4.0 International License (CC BY-NC) (http://www.karger.com/Services/OpenAccessLicense), applicable to the online version of the article only. Usage and distribution for commercial purposes requires written permission. academic degree. Mean F-scale scores and percentage of participants with above-average fat-phobic attitudes $(\geq 3.6)$ significantly decreased only within the intervention group over time ( $p \leq 0.042)$. However, no significant differences between groups over time were observed for AFA scores or factors beliefs to cause obesity. Conclusions: A single exposure to an online education module on weight bias and knowledge about obesity may confer only a modest short-term improvement in medical center employees' fat-phobic attitudes toward people with obesity. Future studies should examine if reexposure to such intervention could impact weight bias, stigma, and discrimination among medical center staff in the long-term. (c) 2022 The Author(s)

Published by S. Karger AG, Basel

\section{Introduction}

Obesity is a complex, progressive, and relapsing chronic disease associated with an elevated risk of adverse health outcomes and premature death and is characterized by abnormal or excess adiposity [1-4]. It is caused by a complex interplay between various factors, including

ClinicalTrials.gov number: NCT04741113.

Correspondence to:

Shiri Sherf-Dagan, shiris@ ariel.ac.il 
host genes, dietary habits, lifestyle, metabolic factors, psychological issues, gut microbiota, and environmental factors [4]. Scientific bodies have recognized obesity as a disease, with the number of people affected by this disease increasing globally [4-9]. However, it has been reported that substantial proportions of health professionals from various health disciplines hold negative attitudes, beliefs, and behaviors towards people with obesity $(\mathrm{PwO})[10$ 14]. Expression of negative attitudes, beliefs, and behaviors towards $\mathrm{PwO}$ among health professionals could include poor communication, spending less clinical contact time, providing less needed information, missing diagnoses, using inappropriate medical equipment, and attributing a considerable part of patient health issues to their excess weight $[10,11,15]$. Experiencing weight bias, stigma, and discrimination by patients may lead to adverse physiological and psychological outcomes such as depression, anxiety, stress, feeling embarrassed about their body size, decreased self-esteem, substance use, and lower quality of life [10, 13-17]. Moreover, patients who internalize these negative beliefs about themselves may develop less adaptive coping responses, including low compliance to medical advice, lack of trust, and avoidance, delay, or cancellation of health services $[10,12,18,19]$. Therefore, strategies to reduce weight bias, stigma, and discrimination among healthcare professionals are needed to create a more accepting, respectful, and effective treatment environment for PwO [10-12, 14]. However, well-designed experimental research to find effective strategies to reduce weight bias, stigma, and discrimination among practicing health professionals is lacking, and no single preferred approach exists [11, 14, 20-25]. The majority of the trials among healthcare professionals were small, included short-term interventions, and showed little or no effect in reducing weight bias [20-25]. Employees of Assuta Medical Centers' must carry out educational modules on various topics such as infection prevention, prevention of sexual harassment, and data security as part of their routine work on an annual basis. Therefore, we decided to carry out an intervention in the form of an educational module that could be integrated into the natural work environment of the employees. This study aimed to evaluate the effect of an online education module on weight bias and knowledge about obesity in Assuta Medical Centers, a chain of private medical centers in Israel. We hypothesized that the participants in the intervention group would better improve their attitudes and beliefs towards $\mathrm{PwO}$ compared to the participants in the control group.

An Intervention to Reduce Weight Bias

\section{Methods}

An open-label parallel randomized controlled trial (RCT) was conducted among employees of Assuta Medical Centers. Assuta Medical Centers, the largest chain of private medical centers in Israel, includes four hospitals and three medical centers with operating rooms and outpatient care. Request for consent to participate in the study was sent by the organization's email address and SMS between January 17 and February 14, 2021, to all employees of Assuta Medical Centers. Employees who confirmed their consent to participate in the study were randomized into intervention or control (i.e., "no intervention") arms using an online software program http://www.randomization.com/, stratifying for gender using permuted blocks for every four participants [26]. To maintain cohesion between the various measures, each participant was assigned a permanent code number that was used throughout the study.

The study intervention included an online 15-min educational module which was administered to participants via a secured link. The educational module was based on the constructive social learning model and composed of four components, including (a) knowledge about obesity, including obesity definition and prevalence, risk factors, and treatment options; (b) weight bias, stigma, and discrimination definitions and impact; (c) strategies to reduce weight bias, stigma, and discrimination in the healthcare setting; (d) a short quiz.

The educational module development was carried out throughout recommended steps [27]. The first step included a comprehensive literature review $[4,15,28,29]$. The second step included the preparation of a preliminary draft of the plan by two investigators (S.S.-D. and Y.K.). The third step included evaluation of the planned educational module in terms of content and face validity by five experts in the field of obesity (three dietitians [V.K.-S., M.B., and L.M.-T.] and two bariatric surgeons [N.S. and A.R.]). Their recommendations were incorporated into the final planned education module. The final version of the module was produced by HRplus Co. (https://hiteachtests.com/customer_files/assutaobesity/story.html).

\section{Data Collection}

At baseline (i.e., right before the intervention), 1 week ("7-day follow-up"), and 1-month post-intervention ("30-day follow-up"), both groups received an anonymous online survey using "Survey Monkey" software by the organization's email address and SMS. The survey was constructed with the assistance of experts in the obesity field and based on validated questionnaires [30-33] with some necessary adaptations. For all original questionnaires (i.e., Anti-Fat Attitudes [AFA] questionnaire [31], short form of fatphobia scale [F-scale] [32], and beliefs about the causes of obesity questionnaire [33]), language (i.e., forward and backward translation) and cultural adaptations were performed in steps according to developed methodologies [34-36]. The last was managed by an expert committee (S.S.-D., Y.K., V.K.-S., and M.B.), who reviewed all the translation versions and achieved equivalence to the original questionnaires in terms of language and culture as recommended $[34,36]$.

Moreover, data on demographics, occupation, current weight and height, self-perception of weight status, and weight history of study participants were collected at baseline. The final stage included a preliminary pilot testing in a small sample of diverse 
healthcare personnel $(n=20)$ to assess the survey's face validity and provide feedback on wording and content [35].

The AFA questionnaire indicates explicit AFA toward PwO and comprises 13 items divided into 3 subscales ("dislike," "fear about fat," and "willpower"). The "dislike" subscale includes seven items and assesses aversion towards $\mathrm{PwO}$ (e.g., "I really don't like fat people much" and "I don't have many friends that are fat"). The "fear about fat" subscale includes three items and assesses personal concerns and distress about weight gain (e.g., "I feel disgusted with myself when I gain weight" and "I worry about becoming fat"). The "willpower" subscale includes three items and assesses the belief that being obese is a matter of personal control (e.g., "Some people are fat because they have no willpower" and "Fat people tend to be fat pretty much through their own fault"). Each item was asked to be ranked on a 10-point Likert-scale response format ( 0 = very strongly disagree; $9=$ very strongly agree). AFA total score and each subscale score were summed up and divided by the number of items used to create the subscale, while higher total scores indicated stronger AFA [31, 37]. This outcome was analyzed solely as a continuous parameter as an acceptable cut-off is not presently available [38].

Short form of F-scale indicates fat-phobic attitudes toward $\mathrm{PwO}$ and comprises 14 pairs of adjectives that are used to describe PwO (e.g., "no willpower" vs. "has willpower," "unattractive" vs. "attractive," "lazy" vs. "industrious," and "weak" vs. "strong"). Each pair of adjectives was asked to be ranked on a 1-5 scale according to the point closest to the adjective name that describes their feelings and beliefs toward $\mathrm{PwO}$. Then, total answers were summed up and divided by the number of items answered, while high scores indicated stronger fat-phobic attitudes [32]. This outcome was analyzed as a continuous parameter. Moreover, a score of $\geq 3.6$ was defined as above the average amount of fat-phobic attitudes, as previously stated [32, 37-39].

Beliefs about the causes of obesity were assessed by having participants rate the importance of 20 factors contributing to obesity. Items included biological (e.g., "genetics," "hormonal disorders," and "side effect of some medications"), behavioral (e.g., "physical inactivity," "high-calorie diet," and "not keeping regular meal times"), and environmental (e.g., "advertising of harmful foods," "high cost of healthy food," and "high availability of low-cost fast food") potential causes. For the present study, nine more factors were added to the original questionnaire based on current literature [4]. Items were rated by using a 5-point Likert-scale response format (1, not at all important; 5 , extremely important). This outcome was analyzed as a continuous parameter.

The study flow is presented in online supplementary Figure 1 (see www.karger.com/doi/10.1159/000521856 for all online suppl. material). The study was approved by the Assuta Medical Centers' Institutional Review Board (\#0008-20ASMC), and the study was preregistered on the NIH registration website (TRIAL no. NCT04741113). The study methods are in accordance with the CONSORT Statement [40].

\section{Statistical Methods}

Statistical analyses were performed using SPSS software version 26. For continuous variables, tests of normality distribution were used. Means of continuous variables were compared between the groups using the independent-samples $t$ test. The prevalence of dichotomous or categorical variables was compared using the $\chi^{2}$ test. Linear mixed model repeated measures analysis was conduct- ed to test differences in continuous variables within and between the study groups over time. To compare dichotomous variables within groups over time, the Cochran Q test was performed. The study endpoints were analyzed according to the intention-to-treat principle. The level of significance for all analyses was set at $p<$ 0.05 . When needed, a Bonferroni correction was used to control for multiple testing.

Cronbach's alpha, a measure of internal consistency, was used to assess the reliability of the AFA and the F-scale. Cronbach's alpha values of $\geq 0.70$ were regarded as satisfactory internal consistency [41].

\section{Results}

\section{Participants' Characteristics}

The survey was administered to all employees of Assuta Medical Centers $(n=3,290)$. As presented in Figure 1, a total of 506 employees agreed to participate in the study (15.4\%) and were randomized to receive the intervention $(n=249)$ or control $(n=257)$. A total of 230 participants (45.5\%) responded to the 7 -day followup survey, and 145 participants responded to the 30day follow-up survey (28.7\%). At the 7 -day follow-up time point, $83.5 \%$ of participants of the intervention group reported they viewed the whole educational module and completed the quiz at the end of the module ("per protocol"), $6.1 \%$ reported they viewed the educational module partially, and $10.4 \%$ reported that they did not view it. Participants who completed the study were older $(45.2 \pm 11.1$ vs. $42.6 \pm 11.7$ years; $p=$ $0.024)$ but had similar gender distribution and mean body mass index (BMI) compared to participants who withdrew from the study. Table 1 presents the characteristics of participants in the survey. The majority of participants were medical secretaries (27.3\%), followed by nurses $(22.3 \%)$ and managerial staff $(15.6 \%)$. Mean participant age was $43.3 \pm 11.6$ years (range: 19-76), $84.6 \%$ were women, and $67.4 \%$ held an academic degree. Mean participant reported BMI was $26.3 \pm 5.1 \mathrm{~kg} /$ $\mathrm{m}^{2}, 21.5 \%$ were found to have obesity according to selfreported weight and height, but only $14.2 \%$ defined themselves as obese, and $40.9 \%$ reported that they are currently attempting to lose weight. No significant differences were found in any of the collected baseline parameters between the study groups. Compared with the group who declined to participate in the survey, the group who agreed to participate in the survey included a higher percentage of women $(84.6 \%$ vs. $76.7 \%, p=$ $0.024)$ and had different occupation distribution $(p<$ $0.001)$. 


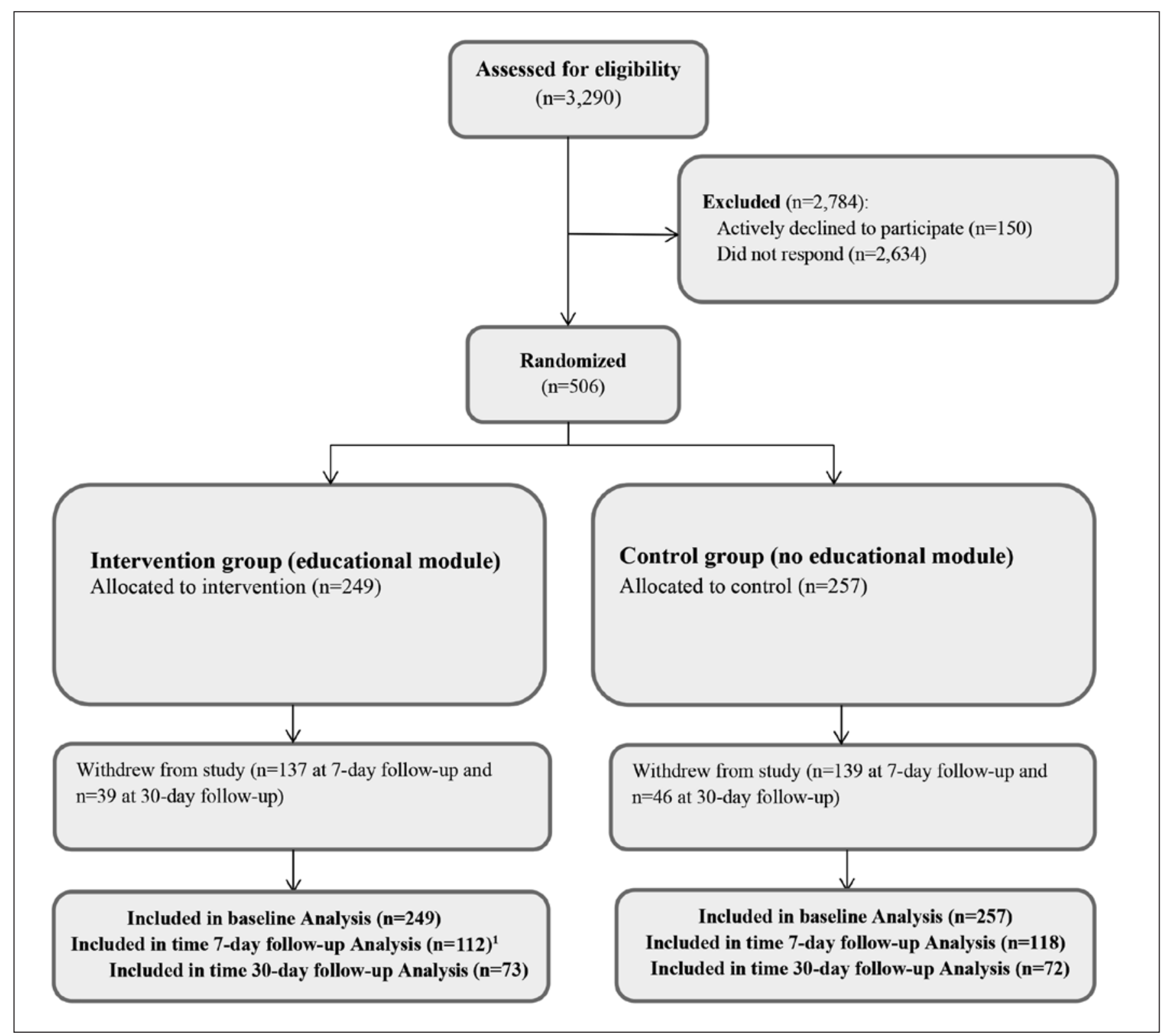

Fig. 1. Flow chart of the study population. ${ }^{1}$ At 7 -day follow-up time point, $83.5 \%$ of participants of the intervention group reported they viewed the whole educational module and completed the quiz at the end of the module ("per protocol"), $6.1 \%$ reported they viewed the educational module partially, and $10.4 \%$ reported that they did not view it.

\section{The AFA Questionnaire}

At all time points and for both study groups, scores of "fear of fat" and "willpower" subscales were higher than the "dislike" subscale. Over time, means of AFA total scores, "fear of fat" subscale scores, and "willpower" subscale scores decreased for both study groups $(p<0.001$ for all), but no significant difference between groups was found. Additionally, no changes were found for the mean "dislike" subscale scores over time for both groups. Moreover, although mean scores for the "willpower" subscale decreased for both groups compared to baseline, they stayed lower until the 30-day follow-up only within the intervention group (Table 2). The internal consistency of the AFA was high at baseline, 7-day follow-up, and 30- 
Table 1. Characteristics of the survey's participants

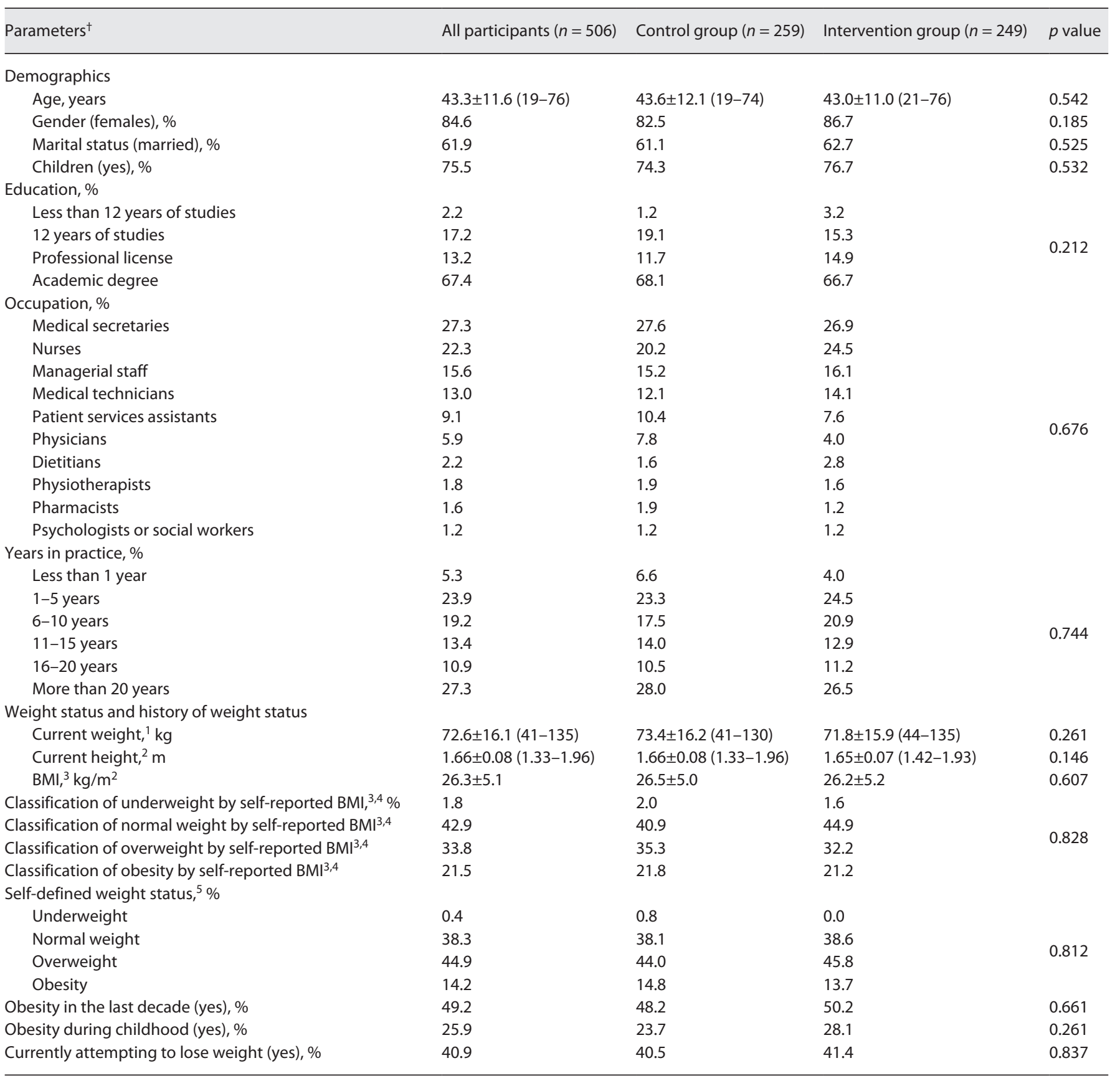

BMI, body mass index. ${ }^{\dagger}$ Values are expressed as mean \pm SD unless otherwise stated. ${ }^{1} n=499$ for this outcome. ${ }^{2} n=501$ for this outcome. ${ }^{3} n=497$ for this outcome. ${ }^{4} \mathrm{BMI}$ of $<18.5 \mathrm{~kg} / \mathrm{m}^{2}$ was considered as underweight, BMl between 18.5 and $25.0 \mathrm{~kg} / \mathrm{m}^{2}$ was considered as normal weight, BMI between 25.0 and 30.0 $\mathrm{kg} / \mathrm{m}^{2}$ was considered as overweight, and BMI of $>30.0 \mathrm{~kg} / \mathrm{m}^{2}$ was considered as obesity. ${ }^{5} n=11$ did not know how to define their current weight status.

day follow-up (Cronbach's $\alpha=0.720,0.776$, and 0.790 , respectively). These relatively high internal consistency outcomes are in accordance with previous studies [31,37, $38]$.

\section{The Short Form of F-Scale}

Over time, mean F-scale scores decreased for both study groups $(p=0.009)$. However, the scores were significantly decreased at the 7-day and 30-day follow-up points com- 
Table 2. Changes in the Anti-Fat Attitudes (AFA) questionnaire scores in the intervention and control groups over time

\begin{tabular}{|c|c|c|c|c|c|c|}
\hline Outcome variable ${ }^{A, B}$ & Group & Baseline & 7-day follow-up & 30-day follow-up & $p$ time $^{1}$ & $\begin{array}{l}p \text { time }^{*} \\
\text { group }^{2}\end{array}$ \\
\hline \multirow[t]{3}{*}{ AFA questionnaire scores } & Intervention & $3.17(0.07)$ & $2.94(0.08)^{a}$ & $2.96(0.10)^{a}$ & \multirow[t]{3}{*}{$<0.001$} & \multirow[t]{3}{*}{0.892} \\
\hline & Controls & $3.27(0.08)$ & $3.01(0.09)^{a}$ & $3.03(0.10)^{a}$ & & \\
\hline & $p$ groups $^{*, 3}$ & 0.307 & 0.507 & 0.184 & & \\
\hline \multicolumn{7}{|l|}{ Scores by domain } \\
\hline \multirow[t]{3}{*}{ Dislike subscale scores } & Intervention & $1.13(0.07)$ & $1.21(0.09)$ & $1.22(0.10)$ & \multirow[t]{3}{*}{0.471} & \multirow[t]{3}{*}{0.523} \\
\hline & Controls & $1.29(0.08)$ & $1.26(0.09)$ & $1.35(0.10)$ & & \\
\hline & $p$ groups $*, 3$ & 0.135 & 0.720 & 0.511 & & \\
\hline \multirow[t]{3}{*}{ Fear of fat subscale scores } & Intervention & $6.15(0.15)$ & $5.74(0.18)^{a}$ & $5.66(0.20)^{a}$ & \multirow[t]{3}{*}{$<0.001$} & \multirow[t]{3}{*}{0.328} \\
\hline & Controls & $6.12(0.16)$ & $5.62(0.19)^{a}$ & $5.27(0.22)^{a}$ & & \\
\hline & $p$ groups $*, 3$ & 0.929 & 0.894 & 0.826 & & \\
\hline \multirow[t]{3}{*}{ Willpower subscale scores } & Intervention & $4.95(0.13)$ & $4.17(0.17)^{a}$ & $4.27(0.19)^{a}$ & \multirow[t]{3}{*}{$<0.001$} & \multirow[t]{3}{*}{0.430} \\
\hline & Controls & $5.05(0.13)$ & $4.45(0.17)^{a}$ & $4.71(0.20)$ & & \\
\hline & $p$ groups $*, 3$ & 0.584 & 0.141 & 0.013 & & \\
\hline
\end{tabular}

${ }^{1} p$ time $=p$ value for changes over time in the two groups. ${ }^{2} p$ time* group $=p$ value for interaction between the trend of change over time and the group effect. ${ }^{3} p$ groups $=p$ value for between-groups differences in each time point. ${ }^{A}$ Data are presented as estimated mean (SE) according to the mixed model analysis. ${ }^{B}$ Data were available at baseline for $n=255$ and $n=249$, at 7-day follow-up for $n=118$ and $n$ $=112$ and at 30-day follow-up for $n=72$ and $n=73$ for the control group and the intervention group, respectively. ${ }^{\text {a Within groups }}$ differences compared to baseline $(p \leq 0.05)$.

Table 3. Changes in the short form of Fat Phobia Scale scores in the intervention and control groups over time

\begin{tabular}{lllllll}
\hline Outcome variable & Group & Baseline & 7-day follow-up & 30-day follow-up & $p$ time $^{1} p$ time* $^{*}$ group $^{2}$ \\
\hline The short form of fat phobia scale scores & Intervention & $3.45(0.04)$ & $3.36(0.05)^{\mathrm{a}}$ & $3.33(0.05)^{\mathrm{a}}$ & & \\
& Controls & $3.41(0.04)$ & $3.40(0.04)$ & $3.37(0.05)$ & $\mathbf{0 . 0 0 9}$ & 0.161 \\
& $p$ groups,3 & 0.445 & 0.330 & 0.473 & & \\
\hline
\end{tabular}

\footnotetext{
${ }^{1} p$ time $=p$ value for changes over time in the two groups. ${ }^{2} p$ time* group $=p$ value for interaction between the trend of change over time and the group effect. ${ }^{3} p$ groups $=p$ value for between-groups differences in each time point. ${ }^{A}$ Data are presented as estimated mean (SE) according to the mixed model analysis. ${ }^{B}$ Data were available at baseline for $n=241$ and $n=232$, at 7-day follow-up for $n=113$ and $n$ $=106$ and at 30-day follow-up for $n=71$ and $n=72$ for the control group and the intervention group, respectively. ${ }^{\text {a }}$ Within groups differences compared to baseline $(p \leq 0.05)$.
}

pared to baseline only within the intervention group, but not within the control group (Table 3). The percent of participants with F-scale scores $\geq 3$.6 significantly declined over time within the intervention group, but not within the control group ( $p=0.042$ and $p=0.607$, respectively) (shown in Fig. 2). The internal consistency of the F-scale was high at baseline, 7-day follow-up, and 30-day follow-up (Cronbach's $\alpha=0.854,0.844$, and 0.858 , respectively). These relatively high internal consistency outcomes are in accordance with previous studies $[32,37,38,42]$.

The Beliefs about the Causes of Obesity Questionnaire According to the mean ranking order of all factors at baseline, the leading factors were overeating, a high-cal- orie diet, and high consumption of processed food. The lowest-ranked factors were eating in restaurants, the high cost of healthy food, and the advertising of foods with harmful substances. No meaningful differences were noted between groups over time for all factors (Table 4).

\section{Discussion}

To better tackle the obesity epidemic, the problem of weight bias, stigma, and discrimination must be addressed $[14,15]$. Therefore, initiatives aimed at preventing this phenomenon in healthcare settings are required 
Fig. 2. Percent of participants with short form F-scale scores of $\geq 3.6$ according to group and time point. Score of $\geq 3.6$ was defined as the above-average amount of fatphobic attitudes. $n=241, n=113, n=71$ and $n=232, n=106, n=72$ for the control and intervention groups at baseline, 7-day follow-up and 30-day follow-up, respectively. No significant differences between groups were found at baseline $(p=0.143)$.

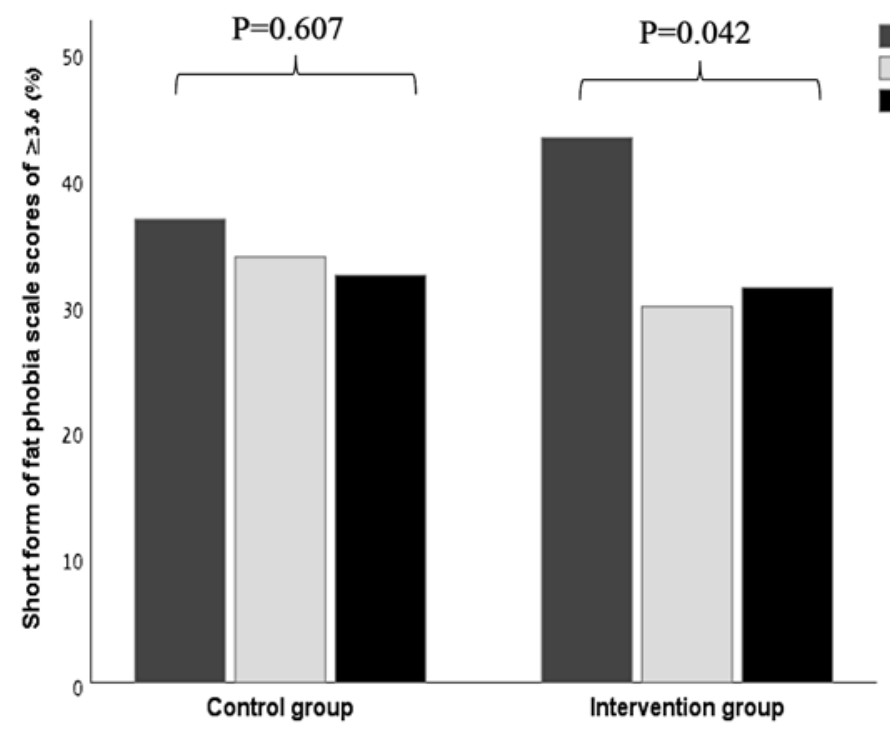

$[13,14]$. In the present study, we aimed to evaluate the effect of an online education module on weight bias and knowledge about obesity among employees of a private chain of medical centers. Our results demonstrated that exposure to a 15-min online intervention modestly reduced fat-phobic attitudes toward $\mathrm{PwO}$, while sustained improvement up to 30 days post-intervention was noticed. However, the intervention did not significantly improve explicit AFA toward $\mathrm{PwO}$ or change the beliefs about the causes of obesity.

To the best of our knowledge, only a limited number of experimental studies to reduce weight bias, stigma, and discrimination among practicing health professionals have been published, while, in most of them, the methodology was flawed, including lack of randomization, lack of control group, and small sample size [11, 20-25]. Moreover, the comparability of previous findings with the present study findings is limited due to differences in study design, target population, intervention implementation, and tools used to assess outcomes. In an RCT conducted on 949 participants, including 150 nurses and 148 physicians, a two-and-a-half-minute animated video with neutral information on obesity and related treatment found that the intervention had no influence on fat-phobic attitudes toward $\mathrm{PwO}$ among all subgroups [25]. A pilot quasi-experiment study ("pretest-posttest design") in 342 public health workers found that participation in a day-long workshop on awareness of weight bias and healthy living led to a significant reduction in explicit AFA toward $\mathrm{PwO}$ and the internalization of media stereotypes and to a significant elevation in self-efficacy to address weight bias immediately post-intervention, while the effects started to decline by the 6-week follow-up [22]. Another quasi-experiment ("posttest-only design") in 266 nurses found that exposure to an annual bariatric sensitivity training by a web-based module which included an overview of obesity, bias, and discrimination in one hospital compared to non-exposure to such training in another hospital was related to better attitudes toward $\mathrm{PwO}$, but not to beliefs toward $\mathrm{PwO}$, regardless of the respondent's BMI [21]. A quasi-experiment ("pretestposttest design") in 30 nurses, patient care technicians, and unit secretaries found that a bariatric sensitivity educational module delivered in a written format effectively decreased weight stigmatization a month after intervention completion [20]. A quasi-experiment ("pretest-posttest design") in 35 physicians and nurses found that exposure to 2 days of an educational intervention for an obesity management program coupled with networking electronic tools improved attitudes toward $\mathrm{PwO}$ after the intervention and at 1-year post-intervention among physicians, but not among nurses [23]. A cluster-RCT in 50 primary care practices found that a brief web-based " $5 \mathrm{~A}$ model" intervention for obesity counseling did not improve weight stigma at 12 months follow-up, but the intervention group showed higher stigma towards $\mathrm{PwO}$ at baseline [24]. Some experimental studies that examined the effect of various delivery platforms of interventions to reduce weight bias among 
Table 4. Changes in the beliefs about the causes of obesity questionnaire in the intervention and control groups over time

\begin{tabular}{|c|c|c|c|c|c|c|}
\hline Outcome variable ${ }^{\mathrm{A}, \mathrm{B}}$ & Group & Baseline & $\begin{array}{l}\text { 7-day } \\
\text { follow-up }\end{array}$ & $\begin{array}{l}\text { 30-day } \\
\text { follow-up }\end{array}$ & $p$ time $^{1}$ & $\begin{array}{l}p \text { time* }^{*} \\
\text { group }^{2}\end{array}$ \\
\hline Physical inactivity & $\begin{array}{l}\text { Intervention } \\
\text { Controls } \\
\text { p groups*,3 }\end{array}$ & $\begin{array}{l}4.14(0.06) \\
4.18(0.06) \\
0.621\end{array}$ & $\begin{array}{l}4.08(0.08) \\
4.06(0.08) \\
0.882\end{array}$ & $\begin{array}{l}4.08(0.09) \\
3.86(0.09)^{a} \\
0.342\end{array}$ & 0.011 & 0.122 \\
\hline Overeating & $\begin{array}{l}\text { Intervention } \\
\text { Controls } \\
p \text { groups }{ }^{*, 3}\end{array}$ & $\begin{array}{l}4.74(0.04) \\
4.69(0.04) \\
0.312\end{array}$ & $\begin{array}{l}4.63(0.05) \\
4.59(0.05) \\
0.711\end{array}$ & $\begin{array}{l}4.66(0.06) \\
4.62(0.07) \\
0.995\end{array}$ & 0.012 & 0.988 \\
\hline High-calorie diet & $\begin{array}{l}\text { Intervention } \\
\text { Controls } \\
\text { p groups*,3 }\end{array}$ & $\begin{array}{l}4.61(0.05) \\
4.52(0.05) \\
0.227\end{array}$ & $\begin{array}{l}4.62(0.06) \\
4.48(0.06) \\
0.148\end{array}$ & $\begin{array}{l}4.63(0.07) \\
4.37(0.07) \\
0.147\end{array}$ & 0.439 & 0.192 \\
\hline High consumption of processed food ${ }^{C}$ & $\begin{array}{l}\text { Intervention } \\
\text { Controls } \\
\text { p groups }{ }^{* 3}\end{array}$ & $\begin{array}{l}4.47(0.05) \\
4.46(0.05) \\
0.894\end{array}$ & $\begin{array}{l}4.56(0.06) \\
4.40(0.07) \\
\mathbf{0 . 0 2 1}\end{array}$ & $\begin{array}{l}4.55(0.07) \\
4.21(0.08)^{a} \\
\mathbf{0 . 0 1 1}\end{array}$ & 0.150 & 0.008 \\
\hline Genetics & $\begin{array}{l}\text { Intervention } \\
\text { Controls } \\
\text { p groups }{ }^{*, 3}\end{array}$ & $\begin{array}{l}4.13(0.06) \\
3.99(0.05) \\
0.055\end{array}$ & $\begin{array}{l}4.01(0.07) \\
3.95(0.07) \\
0.327\end{array}$ & $\begin{array}{l}4.13(0.08) \\
3.91(0.08) \\
0.057\end{array}$ & 0.249 & 0.360 \\
\hline $\begin{array}{l}\text { Psychological disorders (e.g., depression, } \\
\text { anxiety, post-trauma) }\end{array}$ & $\begin{array}{l}\text { Intervention } \\
\text { Controls } \\
p \text { groups }{ }^{*, 3}\end{array}$ & $\begin{array}{l}4.27(0.05) \\
4.18(0.06) \\
0.234\end{array}$ & $\begin{array}{l}4.33(0.07) \\
4.05(0.08) \\
\mathbf{0 . 0 0 3}\end{array}$ & $\begin{array}{l}4.24(0.08) \\
4.02(0.09) \\
0.070\end{array}$ & 0.246 & 0.163 \\
\hline Chronic stress $^{C}$ & $\begin{array}{l}\text { Intervention } \\
\text { Controls } \\
\text { p groups }{ }^{*, 3}\end{array}$ & $\begin{array}{l}4.10(0.05) \\
4.02(0.06) \\
0.329\end{array}$ & $\begin{array}{l}4.26(0.07) \\
3.95(0.08) \\
\mathbf{0 . 0 0 3}\end{array}$ & $\begin{array}{l}4.24(0.08) \\
4.04(0.09) \\
0.052\end{array}$ & 0.415 & 0.088 \\
\hline Lack of willpower & $\begin{array}{l}\text { Intervention } \\
\text { Controls } \\
\text { p groups } *, 3\end{array}$ & $\begin{array}{l}4.12(0.06) \\
4.12(0.06) \\
0.922\end{array}$ & $\begin{array}{l}3.94(0.08) \\
4.04(0.08) \\
0.273\end{array}$ & $\begin{array}{l}3.91(0.09) \\
4.00(0.10) \\
0.517\end{array}$ & 0.021 & 0.619 \\
\hline Metabolic disorders & $\begin{array}{l}\text { Intervention } \\
\text { Controls } \\
p \text { groups } *, 3\end{array}$ & $\begin{array}{l}4.26(0.05) \\
4.22(0.06) \\
0.573\end{array}$ & $\begin{array}{l}4.28(0.07) \\
4.03(0.08)^{a} \\
0.061\end{array}$ & $\begin{array}{l}4.31(0.08) \\
4.14(0.09) \\
0.314\end{array}$ & 0.231 & 0.141 \\
\hline Hormonal disorders & $\begin{array}{l}\text { Intervention } \\
\text { Controls } \\
p \text { groups } * 3\end{array}$ & $\begin{array}{l}4.23(0.05) \\
4.20(0.06) \\
0.743\end{array}$ & $\begin{array}{l}4.29(0.07) \\
4.03(0.08) \\
\mathbf{0 . 0 4 3}\end{array}$ & $\begin{array}{l}4.34(0.08) \\
4.11(0.09) \\
0.161\end{array}$ & 0.495 & 0.035 \\
\hline Side effect of some medications ${ }^{C}$ & $\begin{array}{l}\text { Intervention } \\
\text { Controls } \\
\text { p groups*,3 }\end{array}$ & $\begin{array}{l}4.05(0.06) \\
4.02(0.06) \\
0.758\end{array}$ & $\begin{array}{l}4.22(0.08) \\
3.84(0.08) \\
<\mathbf{0 . 0 0 1}\end{array}$ & $\begin{array}{l}4.24(0.09) \\
3.94(0.10) \\
\mathbf{0 . 0 4 3}\end{array}$ & 0.642 & 0.004 \\
\hline Lack of quantity or quality of sleep ${ }^{C}$ & $\begin{array}{l}\text { Intervention } \\
\text { Controls } \\
\text { p groups*,3 }\end{array}$ & $\begin{array}{l}4.02(0.06) \\
3.94(0.06) \\
0.421\end{array}$ & $\begin{array}{l}4.07(0.08) \\
3.77(0.08) \\
\mathbf{0 . 0 0 1}\end{array}$ & $\begin{array}{l}4.04(0.09) \\
3.78(0.09) \\
\mathbf{0 . 0 1 1}\end{array}$ & 0.366 & 0.086 \\
\hline
\end{tabular}


Table 4 (continued)

\begin{tabular}{|c|c|c|c|c|c|c|}
\hline Outcome variable $\mathrm{A}, \mathrm{B}$ & Group & Baseline & $\begin{array}{l}\text { 7-day } \\
\text { follow-up }\end{array}$ & $\begin{array}{l}\text { 30-day } \\
\text { follow-up }\end{array}$ & $p$ time $^{1}$ & $\begin{array}{l}p \text { time* }^{*} \\
\text { group }^{2}\end{array}$ \\
\hline Not keeping regular meals times ${ }^{C}$ & $\begin{array}{l}\text { Intervention } \\
\text { Controls } \\
\text { p groups }{ }^{*, 3}\end{array}$ & $\begin{array}{l}4.11(0.06) \\
4.12(0.06) \\
0.876\end{array}$ & $\begin{array}{l}4.09(0.08) \\
3.86(0.08)^{a} \\
\mathbf{0 . 0 1 9}\end{array}$ & $\begin{array}{l}3.95(0.09) \\
3.66(0.10)^{a} \\
\mathbf{0 . 0 4 8}\end{array}$ & $<0.001$ & 0.034 \\
\hline $\begin{array}{l}\text { Advertising of harmful foods ("junk } \\
\text { foods") }{ }^{C}\end{array}$ & $\begin{array}{l}\text { Intervention } \\
\text { Controls } \\
\text { p groups }{ }^{*, 3}\end{array}$ & $\begin{array}{l}3.53(0.07) \\
3.49(0.08) \\
0.794\end{array}$ & $\begin{array}{l}3.65(0.10) \\
3.41(0.11) \\
\mathbf{0 . 0 4 8}\end{array}$ & $\begin{array}{l}3.73(0.12) \\
3.42(0.13) \\
0.079\end{array}$ & 0.760 & 0.199 \\
\hline High cost of healthy food ${ }^{C}$ & $\begin{array}{l}\text { Intervention } \\
\text { Controls } \\
\text { p groups } * 3\end{array}$ & $\begin{array}{l}3.34(0.08) \\
3.22(0.08) \\
0.343\end{array}$ & $\begin{array}{l}3.49(0.10) \\
3.27(0.10) \\
0.066\end{array}$ & $\begin{array}{l}3.50(0.11) \\
3.26(0.12) \\
0.140\end{array}$ & 0.274 & 0.654 \\
\hline High availability of low-cost fast food ${ }^{C}$ & $\begin{array}{l}\text { Intervention } \\
\text { Controls } \\
\text { p groups*,3 }\end{array}$ & $\begin{array}{l}3.88(0.06) \\
3.82(0.07) \\
0.581\end{array}$ & $\begin{array}{l}3.98(0.09) \\
3.67(0.09) \\
\mathbf{0 . 0 0 2}\end{array}$ & $\begin{array}{l}3.79(0.10) \\
3.68(0.11) \\
0.377\end{array}$ & 0.242 & 0.078 \\
\hline
\end{tabular}

Beliefs about the causes of obesity by a factor. ${ }^{1} p$ time $=p$ value for changes over time in the two groups. ${ }^{2} p$ time* group $=p$ value for interaction between the trend of change over time and the group effect. ${ }^{3} p$ groups $=p$ value for between-groups differences in each time point. ${ }^{A}$ Data are presented as estimated mean (SE) according to the mixed model analysis. ${ }^{B}$ Data were available at baseline for $n=231$ and $n=222$, at 7-day follow-up for $n=109$ and $n=102$ and at 30-day follow-up for $n=69$ and $n=72$ for the control group and the intervention

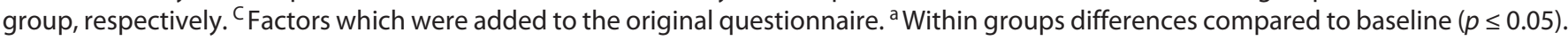

student trainees pursuing a health-related degree have been published in the literature [11]; however, inconsistency in results was noted, and a majority of the studies suffered from methodological weaknesses [11].

One plausible explanation for the less-than-expected results in the present study might be that participants in the intervention group were asked to view the educational module only once and were followed up for 30 days. Therefore, it is possible that a single exposure to the education module content is not enough to create a fundamental change in participant knowledge, thoughts, and beliefs about $\mathrm{PwO}$, and presumably, it is possible that reexposure with long-term follow-up is required. Moreover, the results of the current study may have been affected by the tools used to assess outcomes measured. Fatphobic attitudes toward $\mathrm{PwO}$ were assessed by the F-scale, while the mean baseline F-scale scores in the present study were below the accepted average level of fat-phobia for both study groups and lower than reported in other studies amongst students and health professionals [24, 37, 38, 42-44]. Similarly, the baseline means AFA "dislike" and "willpower" subscales scores in the present study were lower than previous studies in a similar popu- lation $[37,38]$. The great majority of factors that might promote obesity and specifically biological factors were rated much higher in the present study in the beliefs about the causes of obesity questionnaire at baseline compared to previous studies on similar populations [33, 44, 45]. Therefore, it is conceivable that the tools used to assess outcomes in the present study may not have been sensitive enough to detect changes over time. Future studies should also apply qualitative along with quantitative methodologies and assess if educational interventions could cause "real life" improvements in patient care experience.

\section{Strengths and Limitations}

The primary strength of the present study is the use of an RCT methodology to examine the intervention. An additional strength is designing a simple, inexpensive, and practical intervention tool that can be easily integrated into medical center routine. Additional major strengths include the high rates of adherence to protocol, the broad range of medical centers' staff who participated in the study, and the use of validated questionnaires. Nevertheless, some limitations are noteworthy. First, a 
relatively low response rate was achieved (15.4\%). Moreover, although most study participants meet and deliver various services to patients, about $15 \%$ were managerial staff that usually have minimal contact with patients. Thus, selection bias cannot be ruled out. Additionally, high attrition rates in both study groups were observed. A reasonable explanation might be that the study was conducted during the coronavirus period, which could affect healthcare professionals' study participation and completion due to staff shortages and heavy work schedules. However, the study timing was deemed appropriate because obesity is considered a risk factor for unfavorable coronavirus outcomes $[12,46]$. Moreover, the sample size in the present study was larger than previous studies, which have examined similar themes [11, 2025]. Second, the study was performed in a single chain of private medical centers and the follow-up period was short. However, many performed medical procedures are done under non-private health insurance, and about a third of all bariatric procedures in Israel are performed in our centers. Furthermore, in Israel, $24.1 \%$ of adults (age 20-64) were obese as of 2019 [47], and $21.5 \%$ of the participants were found to have obesity according to selfreported weight and height. Therefore, a diverse population, including $\mathrm{PwO}$, is often seen in our centers. Furthermore, this study was conducted in "a real-life setting," increasing the generalizability of our results. Third, the questionnaires were self-reported, and thus might be influenced by social desirability. However, anonymity may have reduced this source of bias. Finally, the Hawthorne effect could affect the study results for both study groups.

\section{Conclusions}

A single exposure to an online education module on weight bias and knowledge about obesity may only modestly improve medical center employees' fat-phobic attitudes toward $\mathrm{PwO}$, even 30 days afterward. Future studies should examine if reexposure to such intervention could impact weight bias, stigma, and discrimination among medical center staff in the long-term.

\section{Acknowledgments}

We thank the study participants for their contribution. We thank Mr. Idan Tapiro for his assistance in study management.

\section{Statement of Ethics}

This study was reviewed and approved by the Ethics Committee of the Assuta Medical Centers (\#0008-20ASMC). The study was preregistered on the NIH registration website (TRIAL no. NCT04741113). All participants were asked to approve their consent by electronic approval.

\section{Conflict of Interest Statement}

The authors have no conflicts of interest to declare.

\section{Funding Sources}

This study was supported by an independent Grant from NovoNordisk. The funder was not involved in the study design, collecting and analyzing the data, writing the report, and submitting this paper for publication.

\section{Author Contributions}

The authors' contributions were as follows - S.S.-D., Y.K., M.B., V.K.-S., N.S., and A.R. designed the research; S.S.-D., Y.K., and L.M.-T. performed the research; S.S.-D. analyzed the data; and S.S.-D., Y.K., and V.K.-.S. wrote the manuscript. All authors read and approved the final manuscript.

\section{Data Availability Statement}

All data generated or analyzed during this study are included in this article and its online supplementary material. Further inquiries can be directed to the corresponding author.

References

Obes Facts 2022;15:384-394

DOI: $10.1159 / 000521856$
1 Whitlock G, Lewington S, Sherliker P, Clarke $\mathrm{R}$, Emberson J, et al. Body-mass index and cause-specific mortality in 900,000 adults: collaborative analyses of 57 prospective studies. Lancet. 2009;373:1083-96.

2 Hannah WN Jr, Harrison SA. Effect of weight loss, diet, exercise, and bariatric surgery on nonalcoholic fatty liver disease. Clin Liver Dis. 2016;20:339-50.

3 Wolfe BM, Kvach E, Eckel RH. Treatment of obesity: weight loss and bariatric surgery. Circ Res. 2016;118:1844-55.

4 Wharton S, Lau DCW, Vallis M, Sharma AM, Biertho L, Campbell-Scherer D, et al. Obesity in adults: a clinical practice guideline. CMAJ. 2020;192:E875-891.

5 Caterson ID, Alfadda AA, Auerbach P, Coutinho W, Cuevas A, Dicker D, et al. Gaps to bridge: misalignment between perception, reality and actions in obesity. Diabetes Obes Metab. 2019;21:1914-24. 
6 Bray GA, Kim KK, Wilding JPH. Obesity: a chronic relapsing progressive disease process. A position statement of the World Obesity Federation. Obes Rev. 2017;18:715-23.

7 Yumuk V, Tsigos C, Fried M, Schindler K, Busetto L, Micic D, et al. European guidelines for obesity management in adults. Obes Facts. 2015;8:402-24.

8 Kyle TK, Dhurandhar EJ, Allison DB. Regarding obesity as a disease: evolving policies and their implications. Endocrinol Metab Clin North Am. 2016;45:511-20.

9 WHO. Obesity and overweight. 2021. Available from: http://www.who.int/mediacentre/ factsheets/fs311/en/ Accessed 2018 Feb 28.

10 Alberga AS, Edache IY, Forhan M, RussellMayhew S. Weight bias and health care utilization: a scoping review. Prim Health Care Res Dev. 2019;20:e116.

11 Alberga AS, Pickering BJ, Alix Hayden K, Ball GD, Edwards A, Jelinski S, et al. Weight bias reduction in health professionals: a systematic review. Clin Obes. 2016;6:175-88.

12 Gupta N, Bombak A, Foroughi I, Riediger N. Discrimination in the health care system among higher-weight adults: evidence from a Canadian national cross-sectional survey. Health Promot Chronic Dis Prev Can. 2020; 40:329-35.

13 Rubino F, Puhl RM, Cummings DE, Eckel $\mathrm{RH}$, Ryan DH, Mechanick JI, et al. Joint international consensus statement for ending stigma of obesity. Nat Med. 2020;26:485-97.

14 Lawrence BJ, Kerr D, Pollard CM, Theophilus M, Alexander E, Haywood D, et al. Weight bias among health care professionals: a systematic review and meta-analysis. Obesity. 2021;29(11):1802-12.

15 Tomiyama AJ, Carr D, Granberg EM, Major B, Robinson E, Sutin AR, et al. How and why weight stigma drives the obesity "epidemic" and harms health. BMC Med. 2018;16:123.

$16 \mathrm{Wu}$ YK, Berry DC. Impact of weight stigma on physiological and psychological health outcomes for overweight and obese adults: a systematic review. J Adv Nurs. 2018;74:103042.

17 Farhangi MA, Emam-Alizadeh M, Hamedi F, Jahangiry L. Weight self-stigma and its association with quality of life and psychological distress among overweight and obese women. Eat Weight Disord. 2017;22:451-6.

18 Sogg S, Grupski A, Dixon JB. Bad words: why language counts in our work with bariatric patients. Surg Obes Relat Dis. 2018;14:68292.

19 Hayward LE, Vartanian LR, Pinkus RT Weight stigma predicts poorer psychological well-being through internalized weight bias and maladaptive coping responses. Obesity. 2018;26:755-61.
20 Falker AJ, Sledge JA. Utilizing a bariatric sensitivity educational module to decrease bariatric stigmatization by healthcare professionals. Bariatr Nurs Surg Patient Care. 2011; 6(2):73-8.

21 Gujral H, Tea C, Sheridan M. Evaluation of nurse's attitudes toward adult patients of size. Surg Obes Relat Dis. 2011;7:536-40.

22 McVey GL, Walker KS, Beyers J, Harrison HL, Simkins SW, Russell-Mayhew S. Integrating weight bias awareness and mental health promotion into obesity prevention delivery: a public health pilot study. Prev Chronic Dis. 2013;10:E46.

23 Baillargeon JP, St-Cyr-Tribble D, Xhignesse M, Brown C, Carpentier AC, Fortin M, et al. Impact of an educational intervention combining clinical obesity preceptorship with electronic networking tools on primary care professionals: a prospective study. BMC Med Educ. 2020;20:361.

24 Welzel FD, Bär J, Stein J, Löbner M, Pabst A, Luppa M, et al. Using a brief web-based 5A intervention to improve weight management in primary care: results of a cluster-randomized controlled trial. BMC Fam Pract. 2021; 22(1):61.

25 Nickel F, Tapking C, Benner L, Schüler S, Ottawa GB, Krug K, et al. Video teaching leads to improved attitudes towards obesity: a randomized study with 949 participants. Obes Surg. 2019;29:2078-86.

26 Suresh K. An overview of randomization techniques: an unbiased assessment of outcome in clinical research. J Hum Reprod Sci. 2011;4:8-11.

27 Arora C, Sinha B, Malhotra A, Ranjan P. Development and validation of health education tools and evaluation questionnaires for improving patient care in lifestyle related diseases. J Clin Diagn Res. 2017;11:JE06-9.

28 Eisenberg D, Noria S, Grover B, Goodpaster $\mathrm{K}$, Rogers AM. ASMBS position statement on weight bias and stigma. Surg Obes Relat Dis. 2019;15:814-21.

29 Ryan DH, Kahan S. Guideline recommendations for obesity management. Med Clin North Am. 2018;102:49-63.

30 Lacroix E, Alberga A, Russell-Mathew S, McLaren L, von Ranson K. Weight bias: a systematic review of characteristics and psychometric properties of self-report questionnaires. Obes Facts. 2017;10:223-37.

31 Crandall CS. Prejudice against fat people: ideology and self-interest. J Pers Soc Psychol. 1994;66:882-94.

32 Bacon JG, Scheltema KE, Robinson BE. Fat phobia scale revisited: the short form. Int $J$ Obes Relat Metab Disord. 2001;25:252-7.
33 Foster GD, Wadden TA, Makris AP, Davidson D, Sanderson RS, Allison DB, et al. Primary care physicians' attitudes about obesity and its treatment. Obes Res. 2003;11:116877.

34 Beaton DE, Bombardier C, Guillemin F, Ferraz MB. Guidelines for the process of crosscultural adaptation of self-report measures. Spine. 2000;25:3186-91.

35 Tsang S, Royse CF, Terkawi AS. Guidelines for developing, translating, and validating a questionnaire in perioperative and pain medicine. Saudi J Anaesth. 2017;11:S80-89.

36 Epstein J, Santo RM, Guillemin F. A review of guidelines for cross-cultural adaptation of questionnaires could not bring out a consensus. J Clin Epidemiol. 2015;68:435-41.

37 Swift JA, Hanlon S, El-Redy L, Puhl RM, Glazebrook C. Weight bias among UK trainee dietitians, doctors, nurses and nutritionists. J Hum Nutr Diet. 2013;26:395-402.

38 Elboim-Gabyzon M, Attar K, Peleg S. Weight stigmatization among physical therapy students and registered physical therapists. Obes Facts. 2020;13:104-16.

39 Pantenburg B, Sikorski C, Luppa M, Schomerus G, König HH, Werner P, et al. Medical students' attitudes towards overweight and obesity. PLoS One. 2012;7:e48113.

40 Schulz KF, Altman DG, Moher D. CONSORT 2010 statement: updated guidelines for reporting parallel group randomised trials. J Pharmacol Pharmacother. 2010;1:100-7.

41 Bland JM, Altman DG. Cronbach's alpha. BMJ. 1997;314:572.

42 Puhl R, Wharton C, Heuer C. Weight bias among dietetics students: implications for treatment practices. J Am Diet Assoc. 2009; 109:438-44.

43 Sikorski C, Luppa M, Glaesmer H, Brähler E, König HH, Riedel-Heller SG. Attitudes of health care professionals towards female obese patients. Obes Facts. 2013;6:512-22.

44 Schwenke M, Luppa M, Pabst A, Welzel FD, Löbner M, Luck-Sikorski C, et al. Attitudes and treatment practice of general practitioners towards patients with obesity in primary care. BMC Fam Pract. 2020;21:169.

45 Phelan SM, Burgess DJ, Burke SE, Przedworski JM, Dovidio JF, Hardeman R, et al. Beliefs about the causes of obesity in a national sample of 4th year medical students. Patient Educ Couns. 2015;98:1446-9.

46 Pearl RL, Schulte EM. Weight bias during the COVID-19 pandemic. Curr Obes Rep. 2021; 10(2):181-90.

47 Israel National Program for Quality Indicators in Community Healthcare. Ministry of health. 2019. Available from: http://www.israelhpr.org.il/quality-measures-program/. 